\title{
Produtividade de pastagens de Coastcross- 1 em consórcio com diferentes leguminosas de ciclo hibernal
}

\author{
Productivity of Coastcross-1 pastures mixed with cool-season legumes
}

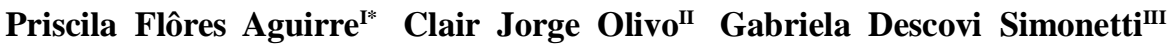 \\ Jéssica Soares Nunes ${ }^{\text {III }}$ Jossiane Ortiz Silva ${ }^{\text {III }}$ Marciele da Silva Santos ${ }^{\text {II }}$ \\ Marcos da Rosa Correa ${ }^{\text {II }}$ Vinícius Felipe Bratz ${ }^{\text {II }}$ Amanda Nunes Assis dos Anjos ${ }^{\mathrm{I}}$
}

RESUMO

Objetivou-se com esta pesquisa avaliar três sistemas forrageiros constituídos por Coastcross-1 (CC) + 100kg de $\mathrm{N} \mathrm{ha}^{-1}$ ano ${ }^{-1}+$ ervilhaca comum; $\mathrm{CC}+100 \mathrm{~kg} \mathrm{de} \mathrm{N} \mathrm{ha}^{-1}$ ano $^{-1}+$ trevo

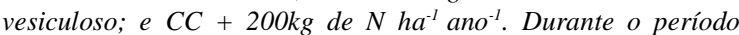
experimental (345 dias), foram realizados treze pastejos. Para avaliação, foram utilizadas vacas em lactação da raça Holandesa. Foram avaliadas a massa de forragem, composição botânica, relação folha/colmo; taxa de acúmulo diário, produção e consumo de forragem; eficiência de pastejo e taxa de lotação. Os valores médios de produção de forragem e lotação foram de 21,0; 20,3 e 24,3t hat ; 7,0; 6,5 e 7,7 unidades animais ha dial $^{-1}$, para os respectivos sistemas forrageiros. Melhores resultados foram obtidos no consórcio de CC com ervilhaca e no cultivo singular de CC.

Palavras-chave: Cynodon, pastejo rotacionado, Trifolium vesiculosum, vacas em lactação, Vicia sativa.

\section{ABSTRACT}

The objective of this research was to evaluate three grazing systems with Coastcross $-1(C C)+100 \mathrm{~kg} \mathrm{~N} \mathrm{ha}^{-1}$ year ${ }^{-1}+$ common vetch; $C C+100 \mathrm{~kg} \mathrm{~N} \mathrm{ha}^{-1}$ year $\mathrm{r}^{-1}+$ arrowleaf clover; and $\mathrm{CC}+200 \mathrm{~kg} \mathrm{~N} \mathrm{ha}^{-1}$ year-1. Thirteen grazing cycles were performed during the experimental period (345 days). Lactating Holstein cows were used in the evaluation. The forage mass, botanical composition, leaf/stem ratio; daily accumulation rate, production and forage intake; grazing efficiency and stocking rate were evaluated. The average of forage production and stocking rate were 21.0, 20.3, 24.3t ha-1 and 7.0, 6.5, 7.7 animal units ha ${ }^{-1}$ day ${ }^{1}$ for the respective forage systems. Better results were found on Coastcross-1 mixed with common vetch and Coastcross-1 alone.

Key words: Cynodon, rotational grazing, Trifolium vesiculosum, lactating cows, Vicia sativa.

\section{INTRODUÇÃO}

A utilização de pastagens do gênero Cynodon tem crescido, especialmente em propriedades leiteiras na região Sul do Brasil. Como vantagens dessas gramíneas, destacam-se o elevado potencial de produção de forragem, resposta à fertilidade do solo, adaptação a diferentes ambientes e flexibilidade de uso como pastagem, feno e silagem (CARNEVALLI et al., 2001). Na maioria das propriedades, essas culturas são estabelecidas singularmente, demandando níveis elevados de adubação nitrogenada. Nessa sistemática, a introdução de leguminosas, devido a sua capacidade de fixação simbiótica do nitrogênio atmosférico, pode reduzir o uso de adubos, além de tornar o ambiente pastoril mais adequado, estendendo o período de utilização do pasto e melhorando a qualidade da forragem.

As leguminosas em geral têm estabelecimento mais lento, devido à menor eficiência fotossintética que as gramíneas, havendo, assim, dificuldade em se consorciar com variedades como Coastcross-1 e Tifton 85, considerando o estabelecimento rápido, alta produção de forragem, o caráter perene e competitivo dessas gramíneas. No entanto, por serem sensíveis ao frio, há possibilidadede se introduzir espécies forrageiras de ciclo hibernal, tanto leguminosas como gramíneas. Dentre as leguminosas, destacam-se a ervilhaca, devido a sua grande capacidade de fixação de $\mathrm{N}$ e produção de

\footnotetext{
IPrograma de Pós-graduação em Zootecnia, Universidade Federal de Santa Maria (UFSM), 97105-900, Santa Maria, RS, Brasil. E-mail: priscilafloresaguirre@yahoo.com.br. *Autor para correspondência.

IIDepartamento de Zootecnia, UFSM, Santa Maria, RS, Brasil.

${ }^{\mathrm{III}}$ Curso de Zootecnia, UFSM, Santa Maria, RS, Brasil. 
massa (SULLIVAN, 2003; PINNOW et al., 2013); e o trevo vesiculoso, que produz forragem com elevado teor de proteína bruta, além do seu alto potencial de fixação de N (LESAMA \& MOOJEN, 1999). Estas leguminosas apresentam ápices de produção distintos da Coastcross-1, diminuindo o risco de concorrência por nutrientes. Assim, objetivou-se com este trabalho avaliar a produtividade de pastagens de Coastcross-1 em consórcio com ervilhaca ou trevo vesiculoso, utilizadas em pastejo com vacas em lactação da raça Holandesa, na região Central do Rio Grande do Sul.

\section{MATERIAL E MÉTODOS}

A pesquisa foi conduzida em área situada na Depressão Central do Rio Grande do Sul, de maio de 2012 a maio de 2013 (345 dias). O solo é classificado como Argissolo Vermelho distrófico arênico. O clima da região é o subtropical úmido (Cfa), conforme classificação de Köppen. Os dados meteorológicos foram obtidos na Estação Meteorológica da UFSM, situada a $500 \mathrm{~m}$ do local da área experimental, aproximadamente. Os valores de temperatura média mensal e precipitação pluviométrica referentes ao período experimental, de maio de 2012 a maio de 2013, foram de $19,3^{\circ} \mathrm{C}, 123,2 \mathrm{~mm}$ mês ${ }^{-1}$; as médias das normais climatológicas para o respectivo período são de $19,5^{\circ} \mathrm{C}, 140,5 \mathrm{~mm}$ mês $^{-1}$. Ao longo do período experimental, foram registradas 20 geadas, sendo seis em junho, doze em julho, uma em setembro de 2012, e uma em maio de 2013. Para avaliação experimental, foi utilizada uma área de $5130 \mathrm{~m}^{2}$ subdividida em nove piquetes. Os tratamentos foram constituídos pelos seguintes sistemas forrageiros: capim bermuda (Cynodon dactylon L. Pers.), cv. 'Coastcross-1' + 100kg de $\mathrm{N} \mathrm{ha}^{-1} \mathrm{ano}^{-1}+$ ervilhaca (Vicia sativa L.), cv. 'Comum'; Coastcross-1 + $100 \mathrm{~kg}$ de N ha-1 ano + trevo vesiculoso (Trifolium vesiculosum Savi), cv. 'Yuchi'; e Coastcross-1 $+200 \mathrm{~kg}$ de $\mathrm{N} \mathrm{ha}^{-1} \mathrm{ano}^{-1}$. A Coastcross-1 já havia sido implantada manualmente na área, utilizandose mudas provenientes da subdivisão de touceiras. Em três piquetes, realizou-se, no mês de maio, a sobressemeadura da ervilhaca, mediante plantio direto, com densidade de $60 \mathrm{~kg} \mathrm{ha}^{-1}$, com espaçamento de $17 \mathrm{~cm}$ entre linhas. Em outros três piquetes, realizou-se, no mesmo período, a sobressemeadura do trevo vesiculoso, mediante plantio direto, com densidade de $8 \mathrm{~kg} \mathrm{ha}^{-1}$, com espaçamento de $17 \mathrm{~cm}$ entre linhas. Também em maio, realizou-se roçada em toda área, permitindose o desenvolvimento do azevém de ressemeadura natural. Fez-se a adubação de base, a partir de análise do solo, conforme recomendação para pastagens perenes de ciclo estival, sendo aplicados $60 \mathrm{~kg} \mathrm{ha}^{-1}$ ano ${ }^{-1}$, tanto de $\mathrm{P}_{2} \mathrm{O}_{5}$, quanto de $\mathrm{K}_{2} \mathrm{O}$. Para a adubação nitrogenada, foram realizadas cinco aplicações, usando-se ureia, conforme cada tratamento, após o $3^{\circ}, 4^{\circ}, 5^{\circ}, 7^{\circ}$ e $8^{\circ}$ pastejo. Após a realização do $9^{\circ}$ pastejo, foi observada a presença da cigarrinha das pastagens (Deois sp.). Para o seu controle, foi aplicado produto biológico (METARRIL ${ }^{\circledR}{ }_{-}$Pesticida biológico cujos ingredientes ativos são esporos do fungo Metarhizium anisopliae). Na realização do pastejo seguinte, verificou-se baixa infestação, indicando a eficácia do produto no controle da cigarrinha. O critério adotado para o início da utilização dos pastos, nas áreas com consórcio, em agosto, foi quando o trevo vesiculoso e a ervilhaca atingiram cerca de 30 e $40 \mathrm{~cm}$ de altura, respectivamente; para as áreas com cultivo singular, foi a altura do dossel do azevém (cerca de $25 \mathrm{~cm}$ ); a partir do sexto pastejo, em meados de dezembro, o critério foi a altura do dossel da Coastcross-1, próxima a $25 \mathrm{~cm}$, para todas as áreas. O método de pastejo utilizado foi o de lotação rotacionada, com um a dois dias de ocupação. A oferta de forragem variou de 4 a $6 \%$ ao longo do ano. Para avaliação, foram utilizadas vacas em lactação da raça Holandesa, com peso médio de $573 \mathrm{~kg}$ e produção média de $17,3 \mathrm{~kg}$ de leite $\mathrm{dia}^{-1}$. Após as ordenhas, as vacas receberam complementação alimentar, correspondente a $0,9 \%$ do peso corporal, a base de milho, soja e premix mineral. Quando não estavam nas áreas experimentais, as vacas foram mantidas em pastagens da época. Antecedendo a entrada dos animais, foi estimada a massa de forragem, mediante técnica com dupla amostragem, efetuando-se cinco cortes rentes ao solo e 20 estimativas visuais, sendo repetida após a retirada dos animais dos piquetes para estimar a massa de forragem residual. A forragem das amostras cortadas foi pesada, sendo retirada uma subamostra para determinação das composições botânica (Coastcross-1, azevém, leguminosas, outras espécies e material morto) e estrutural (para a Coastcross-1). Estes componentes foram secos em estufa de ar forçado a $55^{\circ} \mathrm{C}$ até peso constante para determinação da participação de cada componente. A relação lâmina foliar/colmo + bainha foi obtida pelo quociente dos componentes estruturais da Coastcross-1. A produção total de forragem foi calculada somando-se o acúmulo de forragem em cada intervalo de pastejo. A taxa de acúmulo diário foi calculada subtraindo-se da 
massa de forragem inicial a massa de forragem residual do pastejo anterior, dividindo-se pelo número de dias do intervalo entre pastejos. Para o cálculo da taxa de lotação, dividiu-se o valor da carga animal instantânea pelo número de dias do ciclo do pastejo, e por $450 \mathrm{~kg}$. O consumo aparente de forragem foi estimado pelo método da diferença agronômica, subtraindo-se a massa de forragem residual da massa de forragem inicial, dividindo o resultado pela carga animal. A eficiência de pastejo foi definida pela proporção da forragem produzida que foi consumida pelos animais. A oferta de forragem real foi calculada pelo quociente da massa de forragem inicial e carga animal, multiplicado por 100. Para análise estatística da massa de forragem, foram utilizados os dados dos ciclos de pastejo; para as demais variáveis, foram utilizados os dados médios dos pastejos em cada estação. O delineamento experimental utilizado foi o inteiramente casualizado, com três tratamentos (sistemas forrageiros), três repetições (piquetes) e medidas repetidas no tempo (ciclos de pastejo para massa de forragem/estações para as demais variáveis). Foram considerados como efeitos fixos os níveis de adubação nitrogenada, a presença e o tipo de leguminosa; as variáveis resposta obtidas aos longo dos ciclos de pastejo foram consideradas como medidas aleatórias. Os resultados foram analisados valendo-se do procedimento MIXED e a análise de variância, e as médias comparadas entre si pelo teste $\mathrm{F}$, em nível de $5 \%$ de probabilidade do erro. Quando significativo, o efeito do sistema foi submetido ao teste de Tukey para a comparação de médias, a matriz de covariância utilizada foi a CSH (simetria composta heterogênea).

\section{RESULTADOS E DISCUSSÃO}

No decorrer do período experimental, foram realizados treze pastejos, sendo dois no inverno, quatro na primavera, quatro no verão e três no outono, com um intervalo médio entre pastejos de 25 dias, e tempo de ocupação de um a dois dias. ALVIM et al. (1998), estudando diferentes intervalos de corte em pastagem de Coastcross-1, com adubação de $250 \mathrm{~kg}$ de $\mathrm{N} \mathrm{ha}^{-1}$ ano $^{-1}$, constataram que intervalos de 4 a 5 semanas, na época das chuvas, e 6 a 7 semanas, na época da seca, implicam produção elevada e bom teor de proteína bruta da forragem, com melhor eficiência no aproveitamento do nitrogênio aplicado.

Para a massa de forragem de pré-pastejo (Tabela 1), foram observadas diferenças entre os sistemas forrageiros em oito pastejos. Destes, o consórcio com ervilhaca foi superior $(\mathrm{P}<0,05)$ em seis, ao menos em relação a um dos demais sistemas, tanto nos pastejos iniciais, devido à contribuição

Tabela 1 - Massa de forragem $\left(\mathrm{kg} \mathrm{de} \mathrm{MS} \mathrm{ha}^{-1}\right)$ de diferentes sistemas forrageiros, constituídos por Coastcross-1 $+100 \mathrm{~kg}$ de $\mathrm{N}$ ha ${ }^{-1}$ ano ${ }^{-1}+$

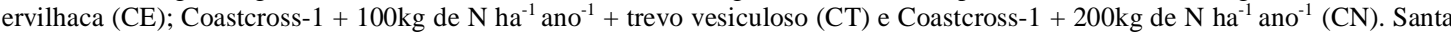
Maria, 2012/2013.

\begin{tabular}{|c|c|c|c|c|c|c|c|c|}
\hline \multirow{2}{*}{ Pastejo } & \multicolumn{3}{|c|}{ 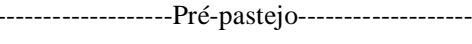 } & \multirow{2}{*}{$\mathrm{CV}(\%)$} & \multicolumn{3}{|c|}{ - } & \multirow{2}{*}{$\mathrm{CV}(\%)$} \\
\hline & $\mathrm{CE}$ & $\mathrm{CT}$ & $\mathrm{CN}$ & & $\mathrm{CE}$ & $\mathrm{CT}$ & $\mathrm{CN}$ & \\
\hline $1^{\circ}$ (ago) & $2752^{\mathrm{aCD}}$ & $2342^{\mathrm{abE}}$ & $1680^{\mathrm{bE}}$ & 8,0 & $1731^{\mathrm{aCDEF}}$ & $1029^{\mathrm{bG}}$ & $979^{\mathrm{bD}}$ & 10,5 \\
\hline $2^{\circ}$ (set) & $3370^{\mathrm{BC}}$ & $3341^{\mathrm{C}}$ & $3233^{\mathrm{CD}}$ & 5,4 & $1574^{\mathrm{bEF}}$ & $2422^{\mathrm{aAB}}$ & $1723^{\mathrm{bC}}$ & 6,9 \\
\hline $3^{\circ}$ (out) & $4038^{\mathrm{abAB}}$ & $4120^{\mathrm{aA}}$ & $3804^{\mathrm{bBC}}$ & 4,5 & $1991^{\text {BCDEF }}$ & $1774^{\mathrm{DE}}$ & $1850^{\mathrm{BC}}$ & 7,0 \\
\hline $4^{\circ}$ (nov) & $2595^{\mathrm{bCD}}$ & $2866^{\mathrm{aD}}$ & $2274^{\mathrm{cDE}}$ & 7,0 & $1715^{\mathrm{DEF}}$ & $1497^{\mathrm{EF}}$ & $1488^{\mathrm{CD}}$ & 8,4 \\
\hline $5^{\circ}$ (nov) & $2118^{\mathrm{D}}$ & $2001^{\mathrm{E}}$ & $2263^{\mathrm{DE}}$ & 8,5 & $1268^{\mathrm{F}}$ & $1284^{\mathrm{FG}}$ & $1415^{\mathrm{CD}}$ & 9,9 \\
\hline $6^{\circ}(\operatorname{dez})$ & $3345^{\mathrm{bBC}}$ & $3809^{\mathrm{abAB}}$ & $4717^{\mathrm{aAB}}$ & 4,6 & $2169^{\mathrm{BCDE}}$ & $2301^{\mathrm{ABC}}$ & $2482^{\mathrm{AB}}$ & 5,6 \\
\hline $7^{\circ}(\mathrm{jan})$ & $4228^{\mathrm{AB}}$ & $3848^{\mathrm{AB}}$ & $5103^{\mathrm{A}}$ & 4,1 & $2347^{\mathrm{abABCDE}}$ & $1949^{\mathrm{bABC}}$ & $2661^{\mathrm{aA}}$ & 5,6 \\
\hline $8^{\circ}($ jan $)$ & $4042^{\mathrm{abAB}}$ & $3594^{\mathrm{bBC}}$ & $4709^{\mathrm{aAB}}$ & 4,4 & $2518^{\mathrm{ABC}}$ & $2157^{\mathrm{CD}}$ & $2499^{\mathrm{AB}}$ & 5,5 \\
\hline $9^{\circ}(\mathrm{fev})$ & $4252^{\mathrm{bAB}}$ & $3853^{\mathrm{bAB}}$ & $4921^{\mathrm{aAB}}$ & 4,2 & $3030^{\mathrm{A}}$ & $2597^{\mathrm{A}}$ & $2858^{\mathrm{A}}$ & 4,6 \\
\hline $10^{\circ}(\operatorname{mar})$ & $4066^{\mathrm{AB}}$ & $3991^{\mathrm{AB}}$ & $4221^{\mathrm{ABC}}$ & 4,4 & $2392^{\mathrm{ABCD}}$ & $2274^{\mathrm{ABC}}$ & $2433^{\mathrm{AB}}$ & 5,5 \\
\hline $11^{\circ}$ (abr) & $4681^{\mathrm{aAB}}$ & $4172^{\mathrm{bA}}$ & $5204^{\mathrm{aA}}$ & 3,8 & $2629^{\mathrm{AB}}$ & $2634^{\mathrm{A}}$ & $2953^{A}$ & 4,8 \\
\hline $12^{\circ}(\mathrm{abr})$ & $3579^{\mathrm{BC}}$ & $3257^{\mathrm{CD}}$ & $3849^{\mathrm{BC}}$ & 5,1 & $3849^{\mathrm{ABCDE}}$ & $2142^{\mathrm{BCD}}$ & $2590^{\mathrm{A}}$ & 5,6 \\
\hline $13^{\circ}$ (mai) & $3585^{\mathrm{abBC}}$ & $3196^{\mathrm{bCD}}$ & $4244^{\mathrm{a} A B C}$ & 4,9 & $2350^{\mathrm{ABCDE}}$ & $2091^{\mathrm{BCD}}$ & $2806^{\mathrm{A}}$ & 5,4 \\
\hline Média & 3589 & 3415 & 3415 & & 2157 & 2012 & 2211 & \\
\hline $\mathrm{CV}(\%)$ & 5,2 & 5,4 & 4,8 & & 6,8 & 7,3 & 6,6 & \\
\hline
\end{tabular}

Médias seguidas por letras distintas, minúsculas na linha e maiúsculas na coluna, diferem entre si $(\mathrm{P}<0,05)$ pelo teste de Tukey. CV= Coeficiente de variação. 
com forragem, quanto posteriormente, nos pastejos conduzidos em janeiro, abril e maio, demonstrando que houve efeito residual dessa leguminosa no sistema forrageiro. Esse resultado corrobora o estudo feito por PINNOW et al. (2013), que, ao trabalharem com a ervilhaca como adubação verde, também verificaram efeito residual, com melhoria da produtividade do trigo. Para o consórcio com trevo vesiculoso, verificou-se superioridade $(\mathrm{P}<0,05)$ na avaliação feita no início de novembro em relação aos demais sistemas. Esse resultado deveu-se à maior contribuição dessa forrageira na estação primaveril. Para a pastagem constituída por Coastcross-1 sob cultivo singular, em que se aplicou o dobro da adubação nitrogenada, verificou-se maior valor no pastejo conduzido em fevereiro, sendo similar a pelo menos um dos consórcios em outros quatro pastejos. Considerando-se a predominância dos resultados, no período hibernal, verificou-se melhor resultado dos consórcios e, no período estival, valores mais elevados foram verificados no sistema envolvendo ervilhaca e na pastagem sob cultivo singular. Quanto à massa de forragem de pós-pastejo, os valores guardam relação com os da massa de forragem de pré-pastejo, tendo-se verificado menor número de diferenças entre sistemas. Embora se tenha usado a mesma oferta de forragem, é provável que tenha ocorrido influência da seleção dos animais nesse resultado, devido à diferença na composição e estrutura dos pastos (OLIVO et al., 2008). Com relação à massa de forragem, entre os pastejos, os valores mais elevados foram observados no período estival, condição esperada para a Coastcross-1. Comparando-se os dados de todas as avaliações, houve menor variabilidade nos consórcios, devido à introdução da leguminosa que tende a equilibrar e estender a disponibilidade de forragem em relação à pastagem em cultivo singular (AZEVEDO JUNIOR et al., 2012).

Quanto à composição botânica (Tabela 2), a ausência de Coastcross-1 nos pastejos realizados no inverno no consórcio com ervilhaca deveu-se à grande participação da leguminosa que interferiu no desenvolvimento da gramínea acompanhante (GRIEU et al., 2001). Essa influência prolongouse nos pastejos efetuados na primavera, com menor participação da Coastcross-1 nos consórcios. No outono, os maiores valores $(\mathrm{P}<0,05)$ observados para a Coastcross-1 na pastagem sob cultivo singular e no consórcio com trevo vesiculoso devem-se, no primeiro, ao maior nível de adubação, considerando que essa forrageira responde bem à fertilização nitrogenada (CORRÊA et al., 2007), e, no segundo, provavelmente pelo maior tempo de participação do trevo no sistema, fornecendo nitrogênio mais regularmente. Com relação à participação das leguminosas, houve superioridade da ervilhaca no inverno e do trevo vesiculoso na primavera. Somente os valores obtidos no inverno para a ervilhaca estão dentro do recomendado por THOMAS (1992), de $30 \%$ de participação de leguminosas, como adequado à sustentabilidade do sistema. Para o azevém, a menor participação no consórcio com ervilhaca, no inverno, deveu-se ao fato de que o período de desenvolvimento destas duas forrageiras é similar; nos pastejos conduzidos na estação primaveril, verificou-se similaridade na participação do azevém nos sistemas. Quanto à fração de outras espécies (espécies de crescimento espontâneo), não houve diferença entre os sistemas forrageiros e, entre as estações, verificou-se maior participação dessas espécies no verão e no outono. Valores inferiores foram relatados por SCARAVELLI et al. (2007), trabalhando com Coastcross-1 com adubação nitrogenada de $80 \mathrm{~kg}$ de $\mathrm{N} \mathrm{ha}^{-1}$ ano $^{-1}$. Na fração material morto, também não houve diferença entre os sistemas, sendo, em média, de 6,7 e 14,4\%, no pré e pós-pastejo, respectivamente, este aumento se dá em função do pisoteio e da seleção dos animais por forragem verde. Os maiores valores foram observados no período estival, devido ao aumento de material senescente da Coastcross-1, notadamente no outono (BORTOLO et al., 2001), e ao efeito cumulativo do pisoteio.

Os valores da relação lâmina foliar/ colmo +bainha da Coastcross-1 foram elevados em todas as estações, obtendo-se médias de 1,17; 0,$9 ; 0,68$ e 0,66 para o pré-pastejo no inverno, primavera, verão e outono, respectivamente. Entre os sistemas, verificou-se diferença somente no inverno, com médias de 1,33 e 1,00 para a Coastcross-1 em consórcio com trevo vesiculoso e cultivada singularmente, respectivamente. Esse resultado é atribuído, provavelmente, à maior adubação nitrogenada, que implica maior desenvolvimento dessa gramínea com maior participação de colmos em relação a folhas na sua composição estrutural, o mesmo comportamento foi observado no inverno, por BARBERO et al. (2009), que, avaliando o consórcio de Coastcross-1com amendoim forrageiro $+100 \mathrm{~kg}$ de $\mathrm{N} \mathrm{ha}^{-1}$ ano $^{-1}$, obtiveram valores de 0,47 e, na pastagem de Coastcross-1, em cultivo singular $+200 \mathrm{~kg}$ de $\mathrm{N} \mathrm{ha}^{-1}$ ano $^{-1}$, de 0,41 . Já para os valores de pós-pastejo, as médias foram de 0,$78 ; 0,44 ; 0,32$ e 0,38 , respectivamente. Para todos os sistemas, houve uma tendência de diminuição dos valores obtidos no decorrer dos pastejos, devido à maturação das plantas (BORTOLO et al., 2001). 
Tabela 2 - Composição botânica de diferentes sistemas forrageiros (SF), constituídos por Coastcross-1 $+100 \mathrm{~kg} \mathrm{de} \mathrm{N} \mathrm{ha}^{-1}$ ano $^{-1}+$ ervilhaca (CE); Coastcross- $1+100 \mathrm{~kg}$ de $\mathrm{N} \mathrm{ha}^{-1}$ ano $^{-1}+$ trevo vesiculoso (CT) e Coastcross- $1+200 \mathrm{~kg} \mathrm{de} \mathrm{N} \mathrm{ha}{ }^{-1}$ ano $^{-1}$ (CN). Santa Maria, $2012 / 2013$.

\begin{tabular}{|c|c|c|c|c|c|c|c|}
\hline \multirow{2}{*}{ Variável } & \multirow{2}{*}{$\mathrm{SF}$} & \multirow[b]{2}{*}{ Inverno } & 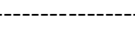 & ões------ & \multirow[b]{2}{*}{ Outono } & \multirow{2}{*}{ Média } & \multirow{2}{*}{$\mathrm{CV}(\%)$} \\
\hline & & & Primavera & Verão & & & \\
\hline \multirow{3}{*}{ Coastcross-1 } & $\mathrm{CE}$ & - & $31,8^{\mathrm{Bb}}$ & $57,0^{\mathrm{a}}$ & $45,7^{\text {Bab }}$ & 33,6 & 10,4 \\
\hline & CT & $1,9^{\mathrm{Bc}}$ & $30,1^{\mathrm{Bb}}$ & $61,7^{\mathrm{a}}$ & $53,1^{\mathrm{Aab}}$ & 36,7 & 9,6 \\
\hline & $\mathrm{CN}$ & $7,1^{\mathrm{Ad}}$ & $38,1^{\mathrm{Ac}}$ & $69,6^{\mathrm{a}}$ & $62,5^{\mathrm{Ab}}$ & 44,3 & 7,9 \\
\hline CV $(\%)$ & & 20,5 & 5,1 & 6,2 & 6,7 & & \\
\hline \multirow{3}{*}{ Azevém } & $\mathrm{CE}$ & $38,2^{\mathrm{B}}$ & 40,9 & - & - & 38,5 & 8,8 \\
\hline & $\mathrm{CT}$ & $75,1^{\mathrm{Aa}}$ & $39,8^{\mathrm{b}}$ & - & - & 57,5 & 6,1 \\
\hline & $\mathrm{CN}$ & $84,6^{\mathrm{Aa}}$ & $44,7^{\mathrm{b}}$ & - & - & 64,7 & 5,4 \\
\hline CV $(\%)$ & & 4,0 & 6,3 & & & & \\
\hline \multirow{2}{*}{ Leguminosa } & $\mathrm{CE}$ & $56,0^{\mathrm{Aa}}$ & $8,8^{\mathrm{Bb}}$ & - & - & 32,4 & 10,0 \\
\hline & $\mathrm{CT}$ & $17,6^{\mathrm{Ba}}$ & $17,3^{\mathrm{Aa}}$ & $5,8^{\mathrm{b}}$ & - & 13,6 & 23,9 \\
\hline $\mathrm{CV}(\%)$ & & 15,3 & 12,1 & & & & \\
\hline \multirow{3}{*}{ Outras espécies } & $\mathrm{CE}$ & $2,1^{\mathrm{b}}$ & $9,5^{\mathrm{b}}$ & $36,3^{\mathrm{a}}$ & $45,2^{\mathrm{a}}$ & 23,3 & 10,5 \\
\hline & CT & $2,2^{\mathrm{c}}$ & $5,8^{\mathrm{c}}$ & $25,6^{\mathrm{b}}$ & $36,8^{\mathrm{a}}$ & 17,6 & 13,9 \\
\hline & $\mathrm{CN}$ & $4,9^{\mathrm{b}}$ & $9,6^{\mathrm{b}}$ & $23,9^{\mathrm{a}}$ & $29,9^{\mathrm{a}}$ & 17,1 & 14,4 \\
\hline $\mathrm{CV}(\%)$ & & 29,9 & 20,4 & 11,9 & 8,1 & & \\
\hline \multirow{3}{*}{ Material morto } & $\mathrm{CE}$ & $3,7^{\mathrm{b}}$ & $9,1^{\mathrm{a}}$ & $6,6^{\mathrm{ab}}$ & $9,1^{\mathrm{a}}$ & 7,1 & 9,0 \\
\hline & CT & $3,2^{\mathrm{c}}$ & $7,0^{\mathrm{b}}$ & $6,9^{\mathrm{b}}$ & $10,2^{\mathrm{a}}$ & 6,8 & 9,4 \\
\hline & $\mathrm{CN}$ & $3,5^{\mathrm{b}}$ & $7,6^{\mathrm{a}}$ & $6,6^{\mathrm{a}}$ & $7,6^{\mathrm{a}}$ & 6,3 & 10,1 \\
\hline $\mathrm{CV}(\%)$ & & 10,9 & 11,7 & 9,2 & 10,0 & & \\
\hline \multirow{3}{*}{ Coastcross-1 } & $\mathrm{CE}$ & - & 29,4 & 44,2 & 39,8 & 28,3 & 8,9 \\
\hline & CT & $2,7^{\mathrm{Ad}}$ & $27,3^{\mathrm{c}}$ & $54,4^{\mathrm{a}}$ & $37,1^{\mathrm{b}}$ & 30,4 & 8,3 \\
\hline & $\mathrm{CN}$ & $6,3^{\mathrm{Bc}}$ & $32,5^{\mathrm{b}}$ & $59,1^{\mathrm{a}}$ & $44,4^{\mathrm{b}}$ & 35,6 & 7,0 \\
\hline $\mathrm{CV}(\%)$ & & 20,5 & 9,9 & 8,0 & 6,4 & & \\
\hline \multirow{3}{*}{ Azevém } & $\mathrm{CE}$ & $57,1^{\mathrm{Ba}}$ & $35,1^{\mathrm{b}}$ & - & - & 46,1 & 7,8 \\
\hline & CT & $76,5^{\mathrm{Aa}}$ & $36,8^{\mathrm{b}}$ & - & - & 56,8 & 6,4 \\
\hline & $\mathrm{CN}$ & $82,5^{\mathrm{Aa}}$ & $36,8^{\mathrm{b}}$ & - & - & 59,6 & 6,0 \\
\hline $\mathrm{CV}(\%)$ & & 4,0 & 8,1 & & & & \\
\hline \multirow{2}{*}{ Leguminosa } & $\mathrm{CE}$ & $30,2^{\mathrm{Aa}}$ & $4,4^{\mathrm{Bb}}$ & - & - & 17,3 & 17,9 \\
\hline & $\mathrm{CT}$ & $8,8^{\mathrm{B}}$ & $10,3^{\mathrm{A}}$ & - & - & 9,6 & 27,9 \\
\hline $\mathrm{CV}(\%)$ & & 15,9 & 29,9 & & & & \\
\hline \multirow{3}{*}{ Outras espécies } & $\mathrm{CE}$ & $2,1^{\mathrm{b}}$ & $12,1^{\mathrm{b}}$ & $42,9^{\mathrm{a}}$ & $41,6^{\mathrm{a}}$ & 24,7 & 11,5 \\
\hline & $\mathrm{CT}$ & $4,3^{\mathrm{c}}$ & $7,4^{\mathrm{c}}$ & $32,9^{\mathrm{b}}$ & $42,8^{a}$ & 21,9 & 13,0 \\
\hline & $\mathrm{CN}$ & $3,9^{\mathrm{b}}$ & $12,0^{\mathrm{b}}$ & $27,6^{\mathrm{a}}$ & $40,5^{\mathrm{a}}$ & 21,0 & 13,6 \\
\hline $\mathrm{CV}(\%)$ & & 19,9 & 16,4 & 14,0 & 3,5 & & \\
\hline \multirow{3}{*}{ Material morto } & $\mathrm{CE}$ & 10,6 & 18,9 & 12,9 & 18,7 & 15,3 & 11,1 \\
\hline & $\mathrm{CT}$ & $7,7^{\mathrm{b}}$ & $18,1^{\mathrm{a}}$ & $12,7^{\mathrm{ab}}$ & $20,1^{\mathrm{a}}$ & 14,6 & 11,5 \\
\hline & $\mathrm{CN}$ & $7,4^{\mathrm{c}}$ & $18,7^{\mathrm{a}}$ & $13,4^{\mathrm{b}}$ & $15,0^{\mathrm{ab}}$ & 13,4 & 12,4 \\
\hline $\mathrm{CV}(\%)$ & & 22,0 & 10,2 & 14,5 & 10,6 & & \\
\hline
\end{tabular}

Médias seguidas por letras distintas, minúsculas na linha e maiúsculas na coluna, diferem entre si $(\mathrm{P}<0,05)$ pelo teste de Tukey. $\mathrm{CV}=$ Coeficiente de variação. 
Para a taxa de acúmulo diário de forragem (Tabela 3), houve melhor desempenho dos consórcios no inverno, em relação à pastagem sob cultivo singular; na primavera, manteve-se a similaridade entre os consórcios com maior valor da Coastcross-1 sem leguminosa, em relação ao sistema envolvendo ervilhaca; no verão, a Coastcross-1 em cultivo singular teve desempenho superior aos consórcios; no outono, as maiores taxas foram verificadas no sistema que recebeu mais adubação nitrogenada e no consórcio com ervilhaca. Comportamento similar foi obtido com a produção de forragem nas distintas estações. Os valores da produção total de forragem são superiores aos obtidos por BARBERO et al. (2009), de 15,6 e 18,4t de MS ha ${ }^{-1}$ ano $^{-1}$ em pastagem de Coastcross-1 em consórcio com amendoim forrageiro $+100 \mathrm{~kg}$ de $\mathrm{N} \mathrm{ha}^{-1}$ ano $^{-1}$ e Coastcross-1 em cultivo singular + $200 \mathrm{~kg} \mathrm{de} \mathrm{N} \mathrm{ha}^{-1} \mathrm{ano}^{-1}$, respectivamente.

Com relação à oferta real de forragem, não houve diferença entre os sistemas, demonstrando que houve equilíbrio na utilização dos pastos. Entre as estações, os valores mais elevados foram ofertados no inverno. O valor médio foi de $5,3 \%$. Para o consumo aparente de forragem, houve diferença $(\mathrm{P}<0,05)$ entre os sistemas somente no verão, com maior valor na pastagem sob cultivo singular em relação ao consórcio com ervilhaca. Esse resultado deve-se, possivelmente, à maior

Tabela 3 - Taxa de acúmulo diário, produção e oferta real de forragem, consumo agronômico, eficiência de pastejo e taxa de lotação de diferentes sistemas forrageiros (SF), constituídos por Coastcross-1 + 100kg de N ha ${ }^{-1}$ ano $^{-1}+$ ervilhaca (CE); Coastcross-1 + $100 \mathrm{~kg} \mathrm{de} \mathrm{N} \mathrm{ha}^{-1}$ ano $^{-1}+$ trevo vesiculoso (CT) e Coastcross-1 + 200kg de N ha ${ }^{-1}$ ano $^{-1}(\mathrm{CN})$. Santa Maria, $2012 / 2013$.

\begin{tabular}{|c|c|c|c|c|c|c|c|}
\hline \multirow{2}{*}{ SF } & \multicolumn{4}{|c|}{ - } & \multirow{2}{*}{ Média } & \multirow{2}{*}{$\mathrm{CV}(\%)$} & \multirow{2}{*}{ Total } \\
\hline & Inverno & Primavera & Verão & Outono & & & \\
\hline \multicolumn{8}{|c|}{ - } \\
\hline $\mathrm{CE}$ & $42,2^{\mathrm{Ac}}$ & $58,4^{\mathrm{Bb}}$ & $83,6^{\mathrm{Ba}}$ & $66,2^{\text {Aab }}$ & 60,7 & 6,8 & \\
\hline CT & $44,7^{\mathrm{Ac}}$ & $61,2^{\mathrm{ABb}}$ & $80,6^{\mathrm{Ba}}$ & $52,6^{\mathrm{Bb}}$ & 58,9 & 6,5 & \\
\hline $\mathrm{CN}$ & $37,8^{\mathrm{Bc}}$ & $69,3^{\mathrm{Ab}}$ & $108,4^{\mathrm{Aa}}$ & $78,2^{\mathrm{Ab}}$ & 70,4 & 5,5 & \\
\hline $\mathrm{CV}(\%)$ & 6,6 & 8,2 & 6,0 & 8,9 & & & \\
\hline \multicolumn{8}{|c|}{-Produção de forragem (t de MS ha $\left.{ }^{-1}\right)$--. } \\
\hline $\mathrm{CE}$ & $4,39^{\mathrm{ABb}}$ & $5,55^{\mathrm{ab}}$ & $6,53^{\mathrm{a}}$ & $4,50^{\mathrm{ABb}}$ & 5,24 & 6,7 & $21,0^{\mathrm{AB}}$ \\
\hline $\mathrm{CT}$ & $4,65^{\mathrm{Ab}}$ & $5,82^{\mathrm{a}}$ & $6,28^{\mathrm{a}}$ & $3,58^{\mathrm{Bc}}$ & 5,08 & 6,9 & $20,3^{\mathrm{B}}$ \\
\hline $\mathrm{CN}$ & $3,93^{\mathrm{Bc}}$ & $6,58^{\mathrm{ab}}$ & $8,46^{\mathrm{a}}$ & $5,32^{\mathrm{Abc}}$ & 6,07 & 5,9 & $24,3^{\mathrm{A}}$ \\
\hline $\mathrm{CV}(\%)$ & 3,8 & 5,1 & 9,0 & 8,2 & & & \\
\hline \multicolumn{8}{|c|}{-Oferta real de forragem (\% do PC) --- } \\
\hline $\mathrm{CE}$ & $6,4^{\mathrm{a}}$ & $5,1^{\mathrm{bc}}$ & $4,1^{\mathrm{c}}$ & $5,5^{\mathrm{ab}}$ & 5,3 & 2,8 & \\
\hline $\mathrm{CT}$ & $6,3^{\mathrm{a}}$ & $5,0^{\mathrm{b}}$ & $4,2^{\mathrm{c}}$ & $5,5^{\mathrm{b}}$ & 5,3 & 2,8 & \\
\hline $\mathrm{CN}$ & $6,4^{\mathrm{a}}$ & $5,0^{\mathrm{b}}$ & $4,1^{\mathrm{c}}$ & $5,4^{\mathrm{b}}$ & 5,2 & 2,9 & \\
\hline $\mathrm{CV}(\%)$ & 4,8 & 3,1 & 0,8 & 0,8 & & & \\
\hline \multicolumn{8}{|c|}{---Consumo aparente de forragem (\% do PC) --- } \\
\hline $\mathrm{CE}$ & $2,9^{\mathrm{a}}$ & $2,0^{\mathrm{b}}$ & $1,6^{\mathrm{Bb}}$ & $2,1^{\mathrm{b}}$ & 2,2 & 7,2 & \\
\hline $\mathrm{CT}$ & $2,9^{\mathrm{a}}$ & $2,3^{\mathrm{ab}}$ & $1,7^{\mathrm{ABb}}$ & $2,0^{\mathrm{b}}$ & 2,2 & 7,1 & \\
\hline $\mathrm{CN}$ & $2,9^{\mathrm{a}}$ & $2,2^{\mathrm{ab}}$ & $1,9^{\mathrm{Ab}}$ & $2,0^{\mathrm{b}}$ & 2,2 & 7,0 & \\
\hline $\mathrm{CV}(\%)$ & 10,6 & 5,9 & 3,1 & 6,4 & & & \\
\hline \multicolumn{8}{|c|}{----Eficiência de pastejo (\% da massa de forragem inicial) ----. } \\
\hline $\mathrm{CE}$ & 44,9 & 40,0 & $38,1^{\mathrm{B}}$ & 37,9 & 40,2 & 5,1 & \\
\hline $\mathrm{CT}$ & 41,4 & 44,9 & $41,2^{\mathrm{AB}}$ & 35,2 & 40,7 & 5,0 & \\
\hline $\mathrm{CN}$ & 43,5 & 42,7 & $44,4^{\mathrm{A}}$ & 36,7 & 41,8 & 4,9 & \\
\hline $\mathrm{CV}(\%)$ & 5,5 & 5,6 & 5,7 & 6,5 & & & \\
\hline & & & -- Taxa de & $\left(\mathrm{UA} \mathrm{ha}^{-1}\right)$ & & & \\
\hline $\mathrm{CE}$ & $3,6^{\mathrm{Ac}}$ & $5,8^{\mathrm{b}}$ & $11,6^{\mathrm{ABa}}$ & $7,1^{\mathrm{ABb}}$ & 7,0 & 5,7 & \\
\hline $\mathrm{CT}$ & $3,2^{\mathrm{ABc}}$ & $6,1^{\mathrm{b}}$ & $10,6^{\mathrm{Ba}}$ & $6,3^{\mathrm{Bb}}$ & 6,5 & 6,1 & \\
\hline $\mathrm{CN}$ & $2,6^{\mathrm{Bc}}$ & $7,1^{\mathrm{b}}$ & $13,1^{\mathrm{Aa}}$ & $7,9^{\mathrm{Ab}}$ & 7,7 & 5,2 & \\
\hline $\mathrm{CV}(\%)$ & 11,8 & 5,8 & 3,1 & 5,2 & & & \\
\hline
\end{tabular}

Médias seguidas por letras distintas, minúsculas na linha e maiúsculas na coluna, diferem entre si $(\mathrm{P}<0,05)$ pelo teste de Tukey. CV= Coeficiente de variação. $\mathrm{PC}=$ Peso corporal.

Ciência Rural, v.44, n.12, dez, 2014. 
disponibilidade de $\mathrm{N}$, implicando melhor valor nutritivo da forragem (CORRÊA et al., 2007) e maior consumo, consequentemente. Entre as épocas, os maiores valores, verificados no período hibernal, devem-se, em parte, à participação elevada do azevém e das leguminosas, no caso dos consórcios (Tabela 2), que normalmente apresentam melhor valor nutritivo, se comparado com espécies forrageiras de ciclo estival.

Para eficiência de pastejo, houve diferença somente no verão, com melhor desempenho na pastagem sob cultivo singular em relação ao consórcio com ervilhaca. Essa diferença também pode ser explicada pela maior disponibilidade de $\mathrm{N}$, como já referenciado. Não foram obtidas diferenças entre as estações. O valor médio de 40,9\% demonstra que não houve limitação no consumo por animal, que, segundo DELAGARDE et al. (2001), ocorre quando a eficiência de pastejo ultrapassa os 50\%.

Para a taxa de lotação, os resultados guardam relação com a produção de forragem, havendo superioridade dos consórcios no inverno; no verão e no outono, taxas mais elevadas foram obtidas na pastagem sob cultivo singular e no consórcio com ervilhaca. Avaliando-se as estações, observa-se que, nos consórcios, houve melhor equilíbrio nas taxas de lotação, notadamente, devido à contribuição das leguminosas no inverno. $\mathrm{O}$ valor médio das estações de verão e outono é 9,4UA $\mathrm{ha}^{-1}$, sendo superior ao observado por SCARAVELLI et al. (2007), de 5,05UA ha-1, avaliando pastagem de Coastcross-1 de janeiro a maio, com adubação nitrogenada de $80 \mathrm{~kg}$ de $\mathrm{N}$ ha ${ }^{-1}$. No decorrer dos pastejos, as maiores lotações foram obtidas, para todos os sistemas, no verão, com média de 11,8UA $\mathrm{ha}^{-1}$. Esse resultado justifica-se pela maior produção de forragem da Coastcross-1 nessa época.

\section{CONCLUSÃO}

Os consórcios com a ervilhaca e o trevo vesiculoso proporcionaram melhor distribuição da forragem ao longo das estações. A introdução da ervilhaca em pastagens de Coastcross- 1 causa atraso no desenvolvimento inicial da gramínea acompanhante. $\mathrm{O}$ consórcio da Coastcross-1 com ervilhaca, recebendo $100 \mathrm{~kg}$ de $\mathrm{N} \mathrm{ha}^{-1}$ ano $^{-1}$ e a pastagem de Coastcross- 1 com adubação nitrogenada de $200 \mathrm{~kg} \mathrm{ha}^{-1} \mathrm{ano}^{-1}$, apresentaram produtividade semelhante.

\section{COMITÊ DE ÉTICA E BIOSSEGURANÇA}

Protocolo 23081016073/2011-27, parecer 113/2011.

\section{REFERÊNCIAS}

AZEVEDO JÚNIOR, R.L. et al. Forage mass and the nutritive value of pastures mixed with forage peanut and red clover. Revista Brasileira de Zootecnia, v.41, n.4, p.827-834, 2012. Disponível em: <http://www.scielo.br/pdf/rbz/v41n4/02.pdf>. doi: 10.1590/S1516-35982012000400002. Acesso em: 14 jan. 2014.

BARBERO, L.M. et al. Produção de forragem e componentes morfológicos em pastagem de coastcross consorciada com amendoim forrageiro. Revista Brasileira de Zootecnia, v.38, n.5, p.788-795, 2009. Disponível em: <http://dx.doi.org/10.1590/ S151635982009000500002>. Acesso em: 10 set. 2013. doi: 10.1590/S1516-35982009000500002.

BORTOLO, M. et al. Avaliação de uma pastagem de Coastcross-1 (Cynodon dactylon (L.) Pers) sob diferentes níveis de matéria seca residual. Revista Brasileira de Zootecnia, v.30, n.3, p.627635, 2001. Disponível em: <http://dx.doi.org/10.1590/S151635982001000300004>. Acesso em: 01 set. 2013. doi: 10.1590/ S1516-35982001000300004.

ALVIM, M. J. et al. Resposta do coast-cross (Cynodon dactylon (L.) Pers.) a diferentes doses de nitrogênio e intervalos de cortes. Revista Brasileira de Zootecnia, v.27, n.5, p.833840, 1998. Disponível em: <http://dx.doi.org/10.1590/S151635982001000300004>. Acesso em: 02 fev. 2014. doi: 10.1590/ S1516-35982001000300004.

CARNEVALLI, R.A. et al. Desempenho de ovinos e respostas de pastagens de coastcross submetidas a regimes de desfolha sob lotação contínua. Pesquisa Agropecuária Brasileira, v.36, n.6, p.919-927, 2001. Disponível em: <http://www.scielo.br/pdf/pab/ v36n6/a10v36n6.pdf>. Acesso em: $10 \mathrm{dez}$. 2013. doi: 10.1590/ S0100-204X2001000600010.

CORRÊA, L.A. et al. Efeito de fontes e doses de nitrogênio na produção e qualidade da forragem de capim-coastcross. Revista Brasileira de Zootecnia, v.36, n.4, p.763-772, 2007. Disponível em: <http://dx.doi.org/10.1590/S151635982007000400003>. Acesso em: 22 ago. 2013. doi: 10.1590/ S1516-35982007000400003.

DELAGARDE, R. et al. Ingestion de l'herbe par les ruminants au paturage. Fourrages, v.166, n.1, p.189-212, 2001. Disponível em: <http://www.afpf-asso.org/index/action/page/id/33/title/ Lesarticles/article/123>. Acesso em: 02 fev. 2014.

GRIEU, P. et al. The mean depth of soil water uptake by two temperate grassland species over time subjected to mild soil water deficit and competitive association. Plant and Soil, v.230, p.197-209, 2001. Disponível em: <http://www.ehleringer.net/Jim/ Publications/268.pdf>. Acesso em: 18 set. 2013.

LESAMA, M.F.; MOOJEN E.L. Produção animal em gramíneas de estação fria com fertilização nitrogenada ou associadas com leguminosa, com ou sem fertilização nitrogenada. Ciência Rural, v.29, n.1, p.123-128, 1999. Disponível em: <http://dx.doi. org/10.1590/S0103-84781999000100022>. Acesso em: 03 out. 2013. doi: 10.1590/S0103-84781999000100022.

OLIVO, C.J. et al. Comportamento ingestivo de vacas em lactação em diferentes sistemas forrageiros. Revista Brasileira de Zootecnia, v.37, n.11, p.2017-2023, 2008. Disponível em: <http://www.scielo.br/pdf/rbz/v37n11/ 
v37n11a18.pdf>. Acesso em: 14 jan. 2014. doi: 10.1590/ S1516-35982008001100018.

PINNOW, C. et al. Qualidade industrial do trigo em resposta à adubação verde e doses de nitrogênio. Bragantia, v.72, n.1, p.20-28, 2013. Disponível em: <http://www.scielo.br/pdf/brag/ v72n1/1653_13.pdf>. Acesso em: 05 maio, 2014. doi: 10.1590/ S0006-87052013005000019.

SCARAVELLI, L.F. et al. Produção e qualidade de pastagens de Coastcross-1 e milheto utilizadas com vacas leiteiras. Ciência Rural, v.37, n.3, p.841-846, 2007. Disponível em: <http://dx.doi.
org/10.1590/S0103-84782007000300037>. Acesso em: 27 ago. 2013. doi: 10.1590/S0103-84782007000300037.

SULLIVAN, P. Overview of cover crops and green manures. California: ATTRA, 2003. 16p. Disponível em: <http://attra.ncat. org/attra-pub/PDF/covercrop.pdf>. Acesso em: 01 out. 2013.

THOMAS, R.J. The role of the legume in the nitrogen cycle of productive and sustainable pastures. Grass and Forage Science, v.47, n.1, p.133-142, 1992. Disponível em: <http://onlinelibrary. wiley.com/doi/10.1111/j.1365-2494.1992.tb02256.x/abstract $>$. doi: 10.1111/j.1365-2494.1992.tb02256.x.

Ciência Rural, v.44, n.12, dez, 2014. 